\title{
SARCOMA SINOVIAL BIFÁSICO EM PACIENTE JOVEM: RELATO DE CASO
}

\author{
Sâmia Israele Braz do Nascimento ${ }^{1}$, Sheezara Teles Lira dos Santos ${ }^{1}$, Maria Taianny Gonçalo de Sál, \\ Alice de Lima de Oliveiral, Rádames Frutuoso Bezerra ${ }^{2}$, Jéssica Késsyla Teixeira Pereiral.
}

Introdução: Os sarcomas sinoviais representam neoplasias malignas incomuns, de crescimento lento, com relação estreita com tendões e articulações. Compreendem de 5\% a $10 \%$ dos sarcomas de tecidos moles. Esses tumores têm origem de células multipotenciais mesenquimais, com maior incidência em jovens, com idade média variando de 15 a 35 anos, observando-se ligeiro predomínio no sexo masculino. Os sarcomas sinoviais são geralmente de tamanho significativo ao diagnóstico, com propensão a metastatizar para linfonodos e pulmões. Objetivo: Descrever um caso de uma paciente jovem diagnosticada em fase avançada de sarcoma sinovial bifásico; Relatar as complicações do sarcoma sinovial bifásico. Descrição do caso: Paciente, LMN, 18 anos, solteira, estudante foi diagnosticada em 27/07/17 com sarcoma sinovial bifásico. O quadro clínico iniciou com o aparecimento de uma lesão tumoral extensa, de rápido crescimento em membro, bastante dolorosa em membro inferior esquerdo. Após a confirmação do diagnóstico por biópsia, foi encaminhada a serviço especializado em Fortaleza. Chegou a realizar 05 sessões de quimioterapia, porém o tratamento foi interrompido, devido à falta de custeio com transporte para se deslocar à capital do estado. Durante os quatro meses sem as sessões de quimioterapia, houve progressão da lesão tumoral e do quadro de anemia, com deterioração do estado geral. Em virtude do agravamento, foi hospitalizada. Depois de 05 dias, retomou as sessões de quimioterapia. Apresentou sangramento volumoso pelo sarcoma, sendo necessárias transfusões de sangue. Devido ao choque hipovolêmico e anemia severa, necessitou de cuidados intensivos. Após solicitação de parecer de cirurgião oncológico, foi realizada a cirurgia de desarticulação coxofemoral esquerda com rotação de retalho miocutâneo de glúteo maior por sarcoma. No pósoperatório evoluiu com pneumonia nosocomial e insuficiência respiratória e que foram revertidos com o tratamento específico. Após duas semanas, necessitou realizar uma transfusão sanguínea devido ao surgimento de melena. A endoscopia digestiva alta não revelou anormalidades. A colonoscopia evidenciou lesões ulcerosas não específicas. O quadro de melena foi superado. Com a melhora do quadro, recebeu alta da UTI para enfermaria, com continuidade ao tratamento. Conclusão: Desse modo, foi descrito um caso de sarcoma sinovial bifásico, em jovem, diagnosticada tardiamente, com interrupção do tratamento e comprometimento do prognóstico.

Palavras-chave: Sarcoma sinovial. Sarcoma sinovial bifásico. Tumores de partes moles.

\footnotetext{
${ }^{1}$ Acadêmica de medicina da Faculdade de Medicina Estácio de Juazeiro do Norte;

${ }^{21}$ Acadêmica de medicina da Faculdade de Medicina da Universidade Federal do Cariri

Autor correspondente: samiabraz8@gmail.com

46 Id on Line Rev. Mult. Psic. V.12, N. 40. 2018 - ISSN 1981-1179

EDIÇÃO ESPECIAL: I CURSO DE ONCOLOGIA DO CARIRI / II JORNADA DE PESQUISA QUANTI-QUALITATIVA EM ONCOLOGIA. JUAZEIRO DO NORTE, 05 A 10 DE MARÇO DE 2018.

Edição eletrônica em http://idonline.emnuvens.com.br/id
} 